\title{
Rainfall Variability and Quantity of Water Supply in Bamenda I, Northwest Region of Cameroon
}

\author{
Zoyem Tedonfack Sedrique and Julius Tata Nfor
}

\section{Contents}

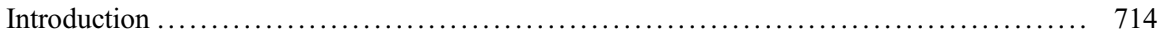

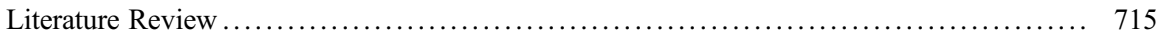

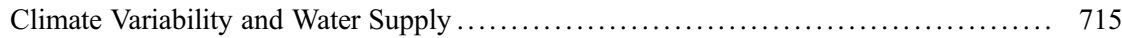

Adaptation to Climate Variability ....................................... 716

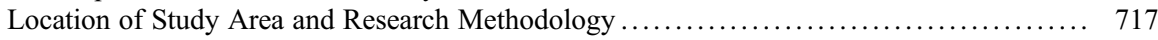

Location of the Study Area ............................................. 717

Research Methodology ................................................. 719

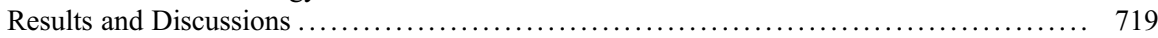

Interannual Rainfall Variability and Anomalies ................................. 720

Monthly Rainfall Variability and Anomalies ................................ 721

Fluctuation in Number of Rainy Days and Rainfall Intensity ................... 722

Analyses of Rainfall Variability in Bamenda I Using Climatic Indices ............... 723

Impacts of Rainfall Variability on Water Supply ........................... 725

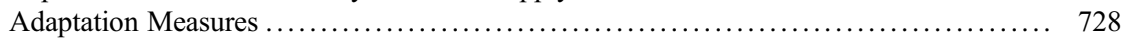

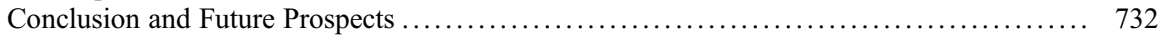

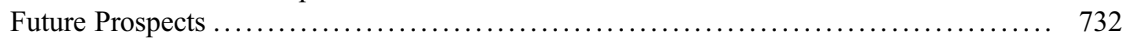

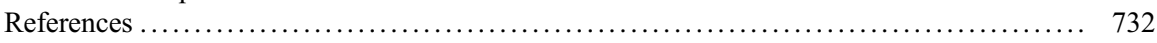

\section{Abstract}

Bamenda I municipality found in the humid tropic is endowed with a dense hydrological network which makes it a water catchment for the entire region. Paradoxically, the region still suffers problems of water shortage. This is due to the spatial and temporal variability in rainfall that greatly affects water supply

This chapter was previously published non-open access with exclusive rights reserved by the Publisher. It has been changed retrospectively to open access under a CC BY 4.0 license and the copyright holder is "The Author(s)". For further details, please see the license information at the end of the chapter.

Z. T. Sedrique $(\bowtie) \cdot J$. T. Nfor

Department of Geography, Planning and Environment, University of Dschang, Dschang, Cameroon e-mail: saiyddouk@gmail.com; jtnfor2007@yahoo.com 
through its impacts on surface and groundwater. For this reason, we came up with the research topic "Rainfall variability and quantity of water supply in Bamenda 1, Northwest Region of Cameroon." The objective of this study is to examine the manifestations of rainfall variability, and how it affects quantity of water supply in the humid tropics. Rainfall data use for this study comprised of annual, monthly, and daily rainfall over a period of 55 years. Water supply data was made of monthly and annual supply. With these data, a Pearson's correlation was computed, and it gave a value of 0.701 , with a rainfall proportion of $49.14 \%$ and $50.86 \%$ for other factors. The seasonality and the Standardized Precipitation Index were equally analyzed. At the end of the study, results showed that rainfall events in Bamenda I fluctuates with time and in space. It equally presented a reduction in the number of rainy days from 204 days in 1663 to 155 in 2018. This led to a reduction in length of rainy season and in rainfall amounts. In addition, the area has witnessed sedimentation of riverbeds and water reservoirs due to erosion and deposition during high rainfall peaks. Equally, floods observed during high rainfall episodes have become a potential threat to water infrastructures imposing exceptional water shortages during the rainy seasons. Due to these, actors in the water supply sector are putting in measures to remedy the situation.

\section{Keywords}

Rainfall variability $\cdot$ Water supply $\cdot$ Stream flow $\cdot$ Water catchment $\cdot$ Vulnerability $\cdot$ Adaptation measures $\cdot$ Bamenda I

\section{Introduction}

The Intergovernmental Panel on Climate Change (IPCC 2008) relates that there is a consensus that increases atmospheric greenhouse gases and will result in climate change which will cause: rise in sea levels, increased frequency of extreme climatic events including intense storms, heavy rainfall events, and droughts. This will increase the frequency of climate-related hazards on water resources. There is less consensus on the magnitude of change in climatic variables, but several studies have shown that climate change will affect the availability and demand for water resources. Tsalefac (2007) and Wilby et al. (2006) defended the idea that if global warming averagely increases, isotherms will be displaced, leading to a modification of ecosystems and hydrological cycle, and therefore consequent impacts on both surface and groundwater. Climate variability in general and rainfall variability in particular are ills that are affecting mankind today with highland areas being the most vulnerable to the changes in climatic patterns and its related impacts on water resources. As such, this work explores the state of rainfall variability in Bamenda I and its impacts on the quantity of water supply. Our aim is to show how changing rainfall pattern in space and in time as well as extreme weather events such as torrential rains, floods, and droughts have led to disastrous impacts on the water resource and on the water system. 
This work analyzes rainfall data from 1963 to 2018 as well as water supply data from 2012 to 2018 with efforts to understand how quantity of water supply has varied with the past and current changes in rainfall patterns. It focuses on the impacts of extreme rainfall events on water supply in the Bamenda I municipality. According to the national plan of action for integrated water resource management (PANGIRE 2013), Cameroon has a dense river network and both surface and groundwater resources are available but not evenly distributed, and both physical and human factors influences the state and availability of its fresh water resources. These factors include climate change, sedimentation of riverbeds, floods, deforestation, physical and chemical contamination, as well as government policies on both waste management and fresh water management. The Bamenda I municipality, found in the humid tropics ought to have had abundant water due to its geographical, geomorphological, geological, and hydrological features. Paradoxically, this region suffers problems of water supply. This is due to the past and current episodes of seasonal droughts and floods caused by heavy and varying rainfall patterns that continue to affects discharge in river basins. The seasonal fluctuations in the quantity of water supply in this locality are equally attributed to the variations in daily, monthly, and annual rainfall variability. These variations have greatly affected the supply of water to the catchment (surface stores), as well as to reservoirs and consequently to different supply points despite the water potentials in the municipality. This work therefore considers rainfall variability as a major constraint to quantity of water supply in the Bamenda I municipality and aims at bringing the impacts of rainfall variability on water supply.

\section{Literature Review}

\section{Climate Variability and Water Supply}

Much has been said on rainfall (climate) variability and water supply, both in the long term and short term. The impacts of climate on water supply can therefore be seen below.

A group of researchers, Beniston (2003), Sadjin et al. (2005), and Martin Dahinden (2010), who studied mountain and climate change, stand for the idea that mountains are among the most sensitive regions to climate change and that some of the most visible indicators of climate change comes from mountain areas. Their ideas were that mountains are water towers of the world as they provide fresh water to more than half of the world's population, but these areas are also among the most sensitive and vulnerable to climate change.

According to Adefolalu (1993) in his study on precipitation, evapotranspiration, and the ecological zones in Nigeria, he explained the fact that during rainy season, it is not expected to have precipitation on daily basis. However, when breaks of equal or more than three pentads (15 days) occur, they are considered serious anomalies. Also, climate change (prolonged dryness) can lead to the drying up of springs, and it is projected to reduce renewable surface water and groundwater resources 
significantly in most dry subtropical regions. This will intend to increase the frequency of meteorological droughts (less rainfall) which is likely to increase the frequency of hydrological drought (less surface water and ground water).

Jiduana et al. (2011) explained the variations in the evolution of rainfall patterns and laid emphasis on the fact that the quantity of rainfall and its duration is experiencing a simultaneous decrease in Nigeria which is remarkable to about $78.6 \%$ while the intensity of the rainy days and rainy season decreased equally to $77.3 \%$. The study equally permitted to analyze that there has been a regression in the stream flow data over the past years in Nigeria, and this is due to a fall in the quantity of rainfall of about $76.8 \%$ affecting the level of stream flow, the stream's transportation capacity, and time of annual recharge. Therefore, it is seen that changes in climate parameters has a potential impact on water supply.

Tsalefac et al. (2007), in their contributions to a book titled Afrique Centrale, le Cameroun et les changements globaux, prospected that a certain number of potential consequences of climate change can be seen in a more or less precise manner. If global warming averagely increases, isotherms will be displaced, leading to a modification of ecosystems, mutations in major vegetation types with a great reduction in the forest surface (wood). Drought will increase in the tropical latitudes and thereby increase the risks of extreme weather conditions. This will lead to a reduction in surface and groundwater. Also, certain ecosystems that are very fragile will be particularly sensible to climate change, notably the mountain and coastal ecosystems.

\section{Adaptation to Climate Variability}

In the phase of hydrological changes and fresh water-related impacts, vulnerability, and risk due to climate change, there is need for adaptation and for increasing resilience. Managing the changing risks due to the impact of climate change is the key to adaptation in the water sector and risk management should be part of decisionmaking and treatment of uncertainty (IPCC 2014). To exploit the impacts of climate change on fresh water, adaptation is generally required; there is growing agreement that an adaptive approach to water management can successfully address uncertainty due to climate change.

According to a group of scholars Mark et al. (2008), adaptation strategies to rainfall variability include household water treatment and safe storage (HWTS), water storage and conservation techniques, water reclamation and reuse technics, increasing use of water-efficient fixtures and appliances. These strategies are grouped in to six typology of adaption technologies which are diversification of water supply, groundwater recharge, preparation for extreme weather events, resilience to water quality degradation, storm water control and capture, and water conservation.

Another group of researchers, ML Parry et al. (2007), in water supply sanitation (WSS) propose sector-specific models, which included upgrading existing infrastructure to meet future challenges and cope with the risks associated with climate 
change. Example, installation of pre-sedimentation pond or riverbank filters for pretreatment, shifting from shallow wells to more reliable sources of water supply, such as surface water and confined aquifers. It was equally concerned with improving water supply through master plan and long-term investment plan including an inventory of groundwater resources. They equally implemented complementary measures, which included the introduction of disaster and climate risk assessment, and improving general framework for risk assessment and management, establishing system for managing floods and other climate and water-related disasters. According to them a proper adaptation could equally be done through protecting water intake facilities from flooding, protecting pumping stations and treatment plants or other facilities potentially exposed to flooding and encouraging the use of alternative water sources, such as (treated) wastewater reuse and rainwater harvesting, to minimize dependence on freshwater and secure access to stable sources of water. Recent experience in Moldova confirms that well properly designed and operated basic treatment plants can deliver even under extreme weather conditions.

\section{Location of Study Area and Research Methodology}

\section{Location of the Study Area}

Bamenda I subdivision is situated Southeast of Mezam division, one of the seven divisions of the Northwest region of Cameroon. It is located within latitude $5^{\circ} 51$ " to $5^{\circ} 58^{\prime \prime}$ north of the equator and longitude $10^{\circ} 8^{\prime \prime}$ to $10^{\circ} 17^{\prime \prime}$ east of the Greenwich meridian, (Fig. 4). It falls within the humid tropical climatic zone and covers a total surface area of about $110 \mathrm{~km}^{2}$ with one main village (Bamendakwe) comprising of about 13 quarters, namely, Abangoh, Achichum, Alahnting, Aningdoh, Banche, Nkar, Ayaba, Ntanche, Ntafebuh, Nta'afi, Moyo, Keneleri, and Abumuchi. This municipality is situated at the entry to Bamenda town, and it is oriented $366 \mathrm{~km}$ northwest of the Cameroon capital with an altitudinal range from about 1269 to $2606 \mathrm{~m}$ above sea level.

As seen on Fig. 1, the Bamenda I municipality is bounded to the north by Bamenda III subdivision, to the south by Santa, to the east by Tubah and Balikumbat, and to the west by Bamenda II subdivision (Flyer Bamenda I council 2018). It is connected to the national territory by the national road $\mathrm{N}^{\circ} 6$. Its geographical location falls within the Guinean climate type. This climate varies from one area to another, and it equally varies with altitudes (thermal gradient) and seasons. The climate is marked by two distinct seasons which are the dry and rainy season. The rainy season is usually from around mid-March to mid-October and sometimes extends to November. The rainfall ranges between 2000 and $2500 \mathrm{~mm}$ per annum and highest amounts are recorded in July and August. Heavy torrential rainfall in this area usually results from strong Southwest Monsoon winds blowing into the country from the Atlantic Ocean. These rainfall amounts lead to a considerable recharge of the water table and consequently an increase in stream volume, thereby leading to adequate supply of water to the entire municipality. 

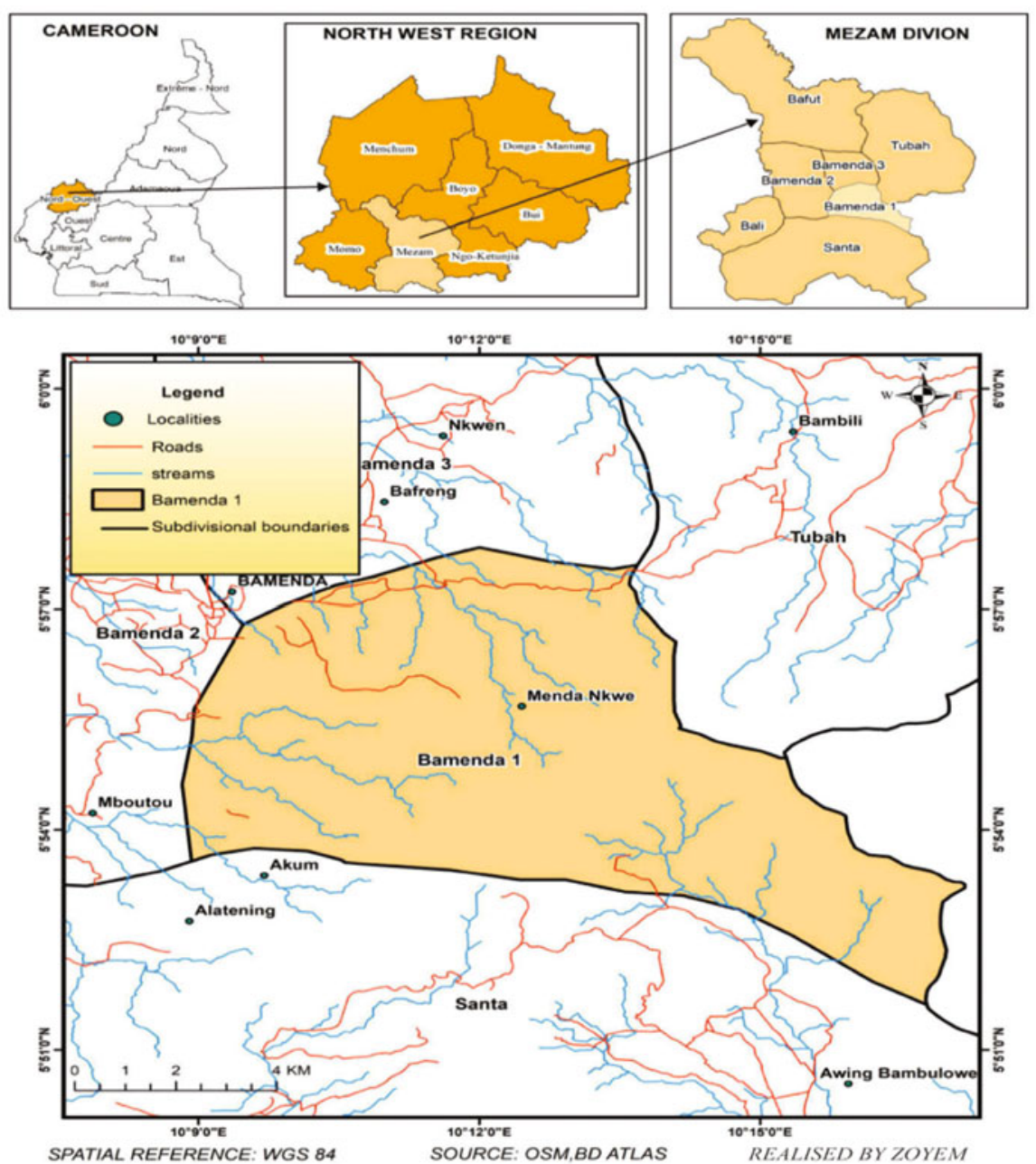

Fig. 1 Location of the study area

On the other hand, dry northeast trade winds from the Sahara Desert blow to the national territory through the northern part of the country, from November to January. The dry season is usually from mid-October and or November to around mid-March. Strong winds and heavy cloud cover characterize the area due to convectional heating. The altitudinal range gives it a highland average temperature of about $19.4{ }^{\circ} \mathrm{C}$ with about $18{ }^{\circ} \mathrm{C}$ around water catchments, confirming the reduction of temperatures with altitudes. Equally, this area registers average relative humidity of about $76.9 \%$. These moderate temperatures are friendly to water conservation as very little is lost through evaporation. On the other hand, high humidity conditions the availability of moisture in the atmosphere. The area also receives 
insulations of about $6-8 \mathrm{~h} /$ day, reaching its peak in January when the northeast trade winds sweeps across the area. This leads to some cloud formations on the highlands of Mendankwe, and during such occurrences, potential cases of convectional rainfall are recorded. These climatic parameters are favorable for the natural supply of water to the catchments and subsequently to the water system there by qualifying this area as a watershed for the entire locality. It is clearly seen on Fig. 1, as most rivers take their rise from the municipality and flows to different areas.

The area is equally located on the western highland plateau, along the Cameroon dorsal, which runs from Mount Cameroon in the southwest passing through Mount Manengouba and Mount Bamboutos in the west, and stretching to Mount Oku in the northwest. High altitudes with series of mountain chains are common in this area. The locality therefore presents a wide range in its relief forms, with altitudes ranging from 1269 to $2606 \mathrm{~m}$. This range permits an ample downflow of water to the rest of the municipality and beyond. The zone is therefore considered a watershed for the entire region since most rivers and streams draining the region take their rise from its highlands.

\section{Research Methodology}

\section{Data Collection}

Both qualitative and quantitative data were gotten from respondents in the zone of study, and the data was from primary as well as secondary sources. Primary data was mostly qualitative and comprised of observations made, interviews conducted, and questionnaires administered to both the water management committee and the local population. This information was obtained using questionnaires and interview guides, where 99 questionnaires were successfully administered to seven quarters and returned. Secondary data were both quantitative and qualitative. Quantitative secondary data comprised of the total quantity of water abstracted and supplied in Bamenda I from 2012 to 2018, collected from the Cameroon Water Utility Corporation (CAMWATER), and of rainfall data for Bamenda Station from 1963 to 2018, collected from the chief in charge of the meteorological station at the Northwest Regional Delegation of Transport. These data were used firstly to characterize rainfall events in the Bamenda I municipality, secondly to determine the Standardized Precipitation Index (SPI) and the rainfall seasonality index, and finally the Pearson's correlation coefficient.

\section{Results and Discussions}

Manifestations of rainfall variability in Bamenda I was evaluated through analyses of interannual rainfall variability and anomalies, analyses of monthly rainfall variability and anomalies, fluctuation in number of rainy days and in rainfall intensity, and through the application of climatic indices. Also, the Pearson's correlation 
coefficient was used to evaluate the extent to which manifestations in rainfall affect water supply quantity. These manifestations have consequent impacts on water resource availability or stream discharge in catchments, on riverbanks and on the water systems. This is due to heavy downpours that cause massive erosion in the drainage basin, landslides along river banks, and sedimentation in water reservoirs.

\section{Interannual Rainfall Variability and Anomalies}

Rainfall variability in Bamenda I manifest through fluctuations in annual rainfall amounts seen as some years registered more rainfall amounts than others. It equally manifest through annual rainfall anomalies as seen on Figs. 2 and 3, respectively.

As seen on Fig. 2, there have been great variations in annual rainfall amounts over the study period. This is seen as some years registered high rainfall amount (above the means of $2362 \mathrm{~mm}$ ), while others registered low rainfall amounts (below the mean). High amounts of rainfall where registered in $1963(2800 \mathrm{~mm})$, in 1969 $(2900 \mathrm{~mm})$, in $1981(2500 \mathrm{~mm})$, and in $2018(2400 \mathrm{~mm})$, while low rainfall amounts were registered in $1972(2200 \mathrm{~mm})$, in $1973(1800 \mathrm{~mm})$, in 2014 (2000), and in 2016 $(1600 \mathrm{~mm})$. There have been a general fall in rainfall amount over the past 55 years, indicated by the depressing trend line. This is in line with global trends of falling rainfall with time due to changing climate, IPCC (2008).

On the other hand, Fig. 3 illustrates rainfall anomalies, and it is seen as some years registered positive rainfall anomalies and others negative rainfall anomalies. Example positive anomalies were recorded in years like 1963, 1969, 1976, 1979, and in 2002. They registered anomalies ranging between 300 and $500 \mathrm{~mm}$, while negative anomalies were recorded in 1964, 1973, 2015, 2016, and 2017 with anomalies between 400 and $900 \mathrm{~mm}$. Negative anomalies registered a frequency $60 \%$ against $40 \%$ for positive anomalies reason for the falling trends.

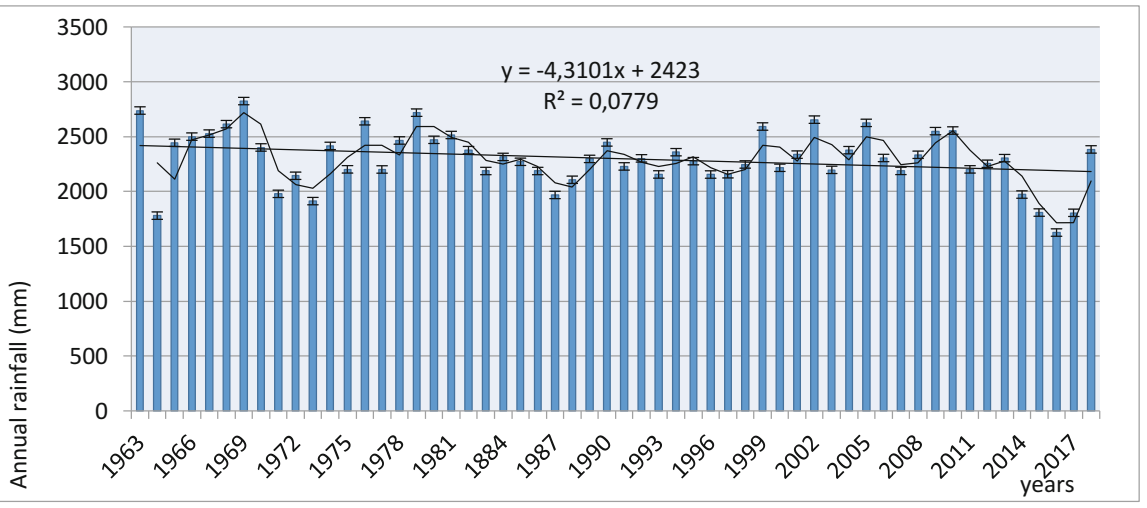

Fig. 2 Interannual rainfall variability in Bamenda up station. (Source: Author (2019)) 


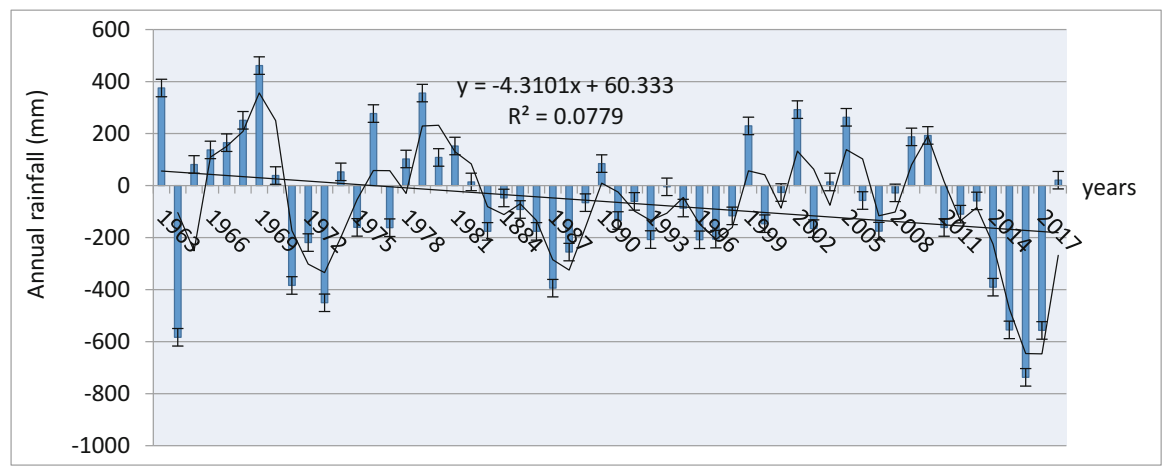

Fig. 3 Interannual rainfall anomalies in Bamenda up station. (Source: Author (2019))

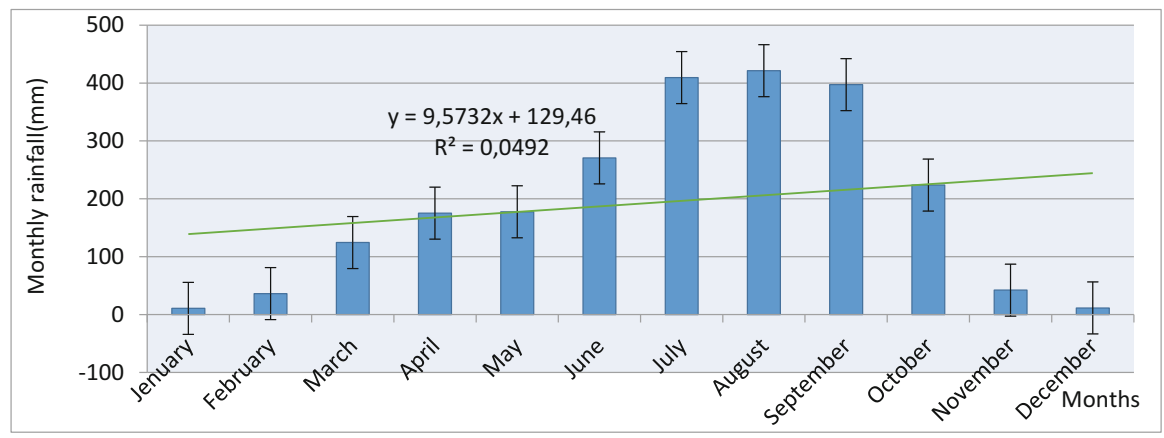

Fig. 4 Monthly rainfall variability. (Source: Author (2019))

\section{Monthly Rainfall Variability and Anomalies}

Rainfall variability equally manifests through fluctuations in monthly rainfall amounts and anomalies, but fluctuations follow a seasonal pattern. The mean monthly rainfall was calculated at $191.68 \mathrm{~mm}$ and fluctuations went both below and beyond the mean, indicating variations rainfall (Fig. 4).

As seen on Fig. 4, rainfall amounts are lower in months of January with about $10 \mathrm{~mm}$, February with $35 \mathrm{~mm}$, November $(42 \mathrm{~mm})$, and December with about $11 \mathrm{~mm}$, as they all register rainfall below the mean of $191.68 \mathrm{~mm}$. The rainfall begins to rise in the months of March $(120 \mathrm{~mm})$, which mark the beginning of the rainy season. Its reaches its peak in July $(410 \mathrm{~mm})$, and August $(420 \mathrm{~mm})$, and starts falling around October $(220 \mathrm{~mm})$.

Rainfall variability in the Bamenda I municipality is equally indicated by monthly rainfall anomalies. This is seen as some months record positive rainfall anomalies while others record negative anomalies (Fig. 5).

Figure 5 on the other hand illustrate monthly rainfall anomalies, and it is seen that negative anomalies were recorded in some rainy months (March, April and May). 


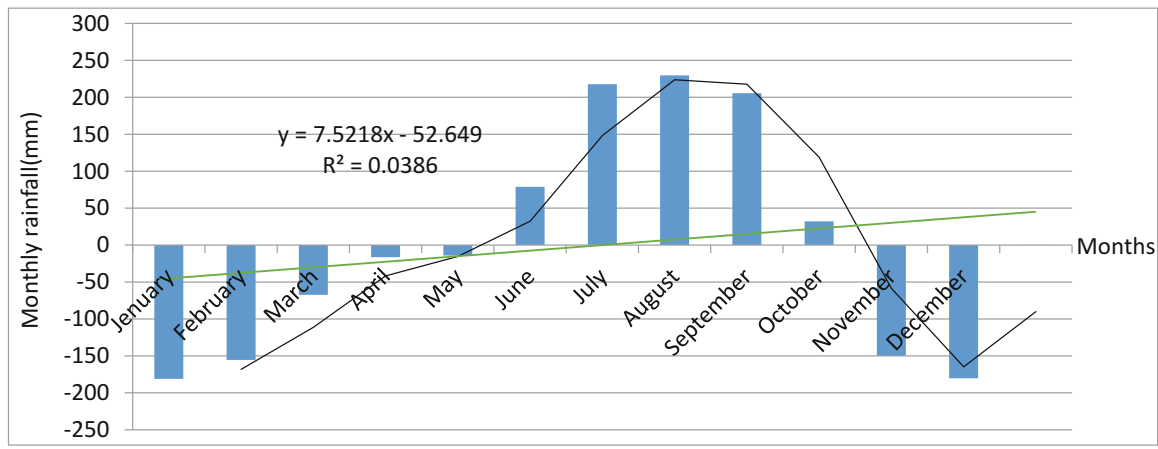

Fig. 5 Monthly rainfall anomalies. (Source: Author (2019))

This is paradoxical because negative anomalies are expected in months of the dry season, but they are instead recorded in rainy months. This may be accounted for by the late onset of rains leading to an increase of the length of the dry season. This will lead to a drop in the water table, thereby reducing water level in catchment and thus exacerbating water shortages. This confirms the results of Hayward et al. (1987) that "an increase in the length of time for recharge of ground water due to prolonged dry season will cause a drop in the water table and a drying up of some streams and springs on which people depend for survival."

\section{Fluctuation in Number of Rainy Days and Rainfall Intensity}

Variation in the number of rainy days and changes in rainfall intensity are other indicators of rainfall variability. This variation has a link with fluctuations in the dates of onset and retreat of rains. This link is seen as years with late onset and early retreat will have a higher tendency of registering less rainy days but with higher rainfall intensity while years with early onset and late retreat will have higher chances of recording many rainy days but less rainfall intensities.

Figure 6 shows variability in rainy days in Bamenda up station from 1963 to 2018. This study period has registered a lot fluctuation in number of rainy days as some years registered close to 250 rainy days annually and others about 130 rainy days. Highest number of rainy days were recorded in 1999 (249 days) and in 2007 (225 days). On the other hand, 1964 and 2011 had the least number of rainy days (135 days and 130 days, respectively). The annual difference in number of rainy days is about 119 days, which is much enough to attest that there have been variations in rainfall within the study area. This is because fluctuations in number of rainy days will obviously lead to fluctuations in frequency and intensity of rainfall. This is felt as years with less rainy days and more rainfall amount record high rainfall intensity, while those with more rainy days and less rainfall amount record less rainfall intensity. This is because less rainfall amount is rationed within 


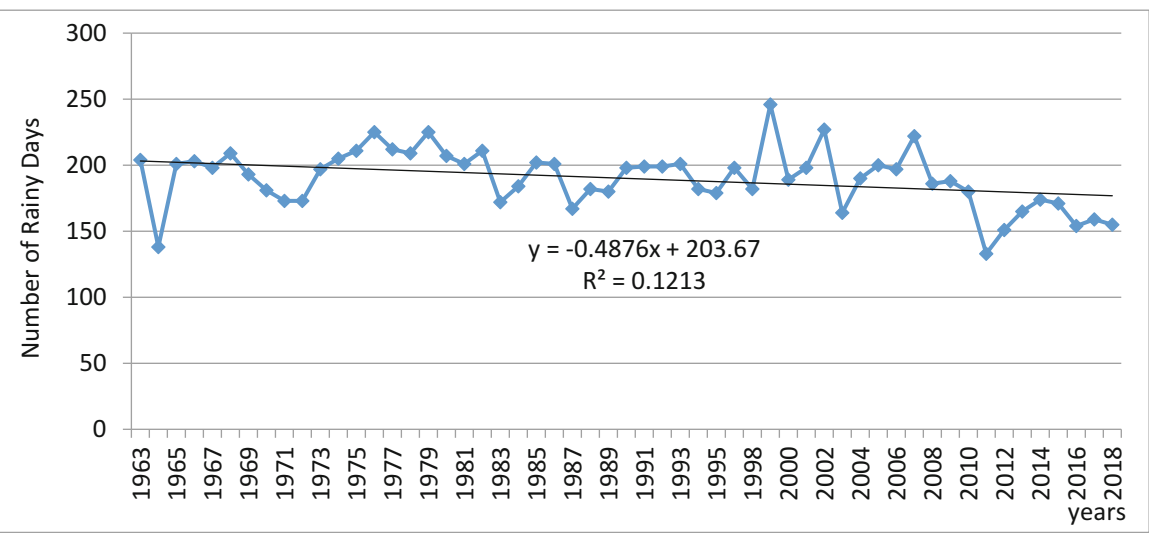

Fig. 6 Number of rainy days. (Source: Author (2019))

Table 1 Classification of SPI values, categories, and corresponding proportions

\begin{tabular}{l|l|c}
\hline SPI value & Category & Probability (\%) \\
\hline 2.00 or more & Extreme wet & 0.3 \\
\hline 1.5 to 1.99 & Severely wet & 2.4 \\
\hline 1.00 to 1.49 & Moderately wet & 11.2 \\
\hline $\mathbf{0}$ to $\mathbf{0 . 9 9}$ & Mildly wet & $\mathbf{3 0 . 1}$ \\
\hline $\mathbf{0}$ to $-\mathbf{0 . 9 9}$ & Mild drought & $\mathbf{3 7 . 4}$ \\
\hline-1.00 to -1.49 & Moderate drought & 14.2 \\
\hline-1.50 to -1.99 & Severe drought & 4.4 \\
\hline-2 or less & Extreme drought & 0 \\
\hline
\end{tabular}

Source: McKee et al. (1993)

the many rainy days and consequently, low rainfall intensity, whereas with the few rainy days, much rainfall amount is pouring per unit area, and hence high rainfall intensity.

\section{Analyses of Rainfall Variability in Bamenda I Using Climatic Indices}

Climatic indices were equally used to characterize rainfall variability in Bamenda I, and both the seasonality and the standardized precipitation index were used (Tables 1 and 2).

\section{The Standardized Precipitation Index (SPI)}

The Standardized Precipitation Index (SPI) is a tool used primarily for defining and monitoring drought and floods (rainfall situation). It equally serves as a method of 
assessing climatic variability. It was developed by McKee et al. in 1993. It was therefore used to access the situation of rainfall variability in Bamenda I (Table 1).

As seen on Table 1, $0.3 \%$ of the study period registered SPI values greater than or equal to 2.00 indicating extreme wet conditions. This implies that the probability of occurrence of extreme floods in Bamenda $\mathrm{I}$ is $0.3 \%$. Equally, 2.4\% of the study period registered values between $1.5 \%$ and $1.99 \%$ corresponding to severely wet conditions. Also, $11.2 \%$ recorded moderately wet and $30.1 \%$ recorded mildly wet conditions. To what concerns drought conditions, $37.4 \%$ lived mild drought, $14.2 \%$ lived moderate drought, and $4.4 \%$ lived severe drought conditions, but no situation of extreme drought was witnessed. The SPI therefore indicates that mild wet and mild drought conditions are most common in Bamenda I since they have the highest probability of occurrence.

\section{The Seasonality Index}

The seasonality of precipitation refers to the tendency for a place to have more rainfall in certain months than in others. It therefore determines the rainfall regime of a particular place (length of seasons). This makes use of the seasonality index (SI) of Walsh and Lawler (1981). Table 2 presents the seasonality index for Bamenda I.

Table 2 shows the scale (class limit) of the seasonality index and their corresponding seasonal regime. The seasonality index for Bamenda up station is calculated at an overall value of $\mathbf{0 . 9 0 1}$, and as seen on the scale, this value falls within the limit $\mathbf{0 . 8 0}$ to 0.99 . This means that the rainfall regime for Bamenda station portrays a markedly seasonal with a long drier season instead of a seasonal regime. Instead of seasonal because humid tropics (Bamenda) are characterized by two distinct seasons, so we should normally have a "seasonal" rainfall regime with a well-defined rainy and dry season but instead of a seasonal regime, it shifted to a "markedly seasonal with long drier season." This is a clear indicator of a variation in rainfall, and it also indicates that rainfall in Bamenda I has been reducing gradually, leading to higher trends of drought occurrence. This result is in line with that of Jiduana et al. (2011), in Northern Nigeria, which emphasizes on the fact that "rainfall amounts and its duration is experiencing a general decrease." This explains why rainy months of March, April, and May portray negative anomalies, with rainfall

Table 2 Rainfall seasonality index and corresponding regimes

\begin{tabular}{l|l}
\hline Seasonality index class limit & Rainfall regime \\
\hline$\leq 0.19$ & Very equable \\
\hline $0.20-0.39$ & Equable but with a definite wetter season \\
\hline $0.40-0.59$ & Rather seasonal with a short drier season \\
\hline $0.60-0.79$ & Seasonal \\
\hline $\mathbf{0 . 8 0}-\mathbf{0 . 9 9}$ & Markedly seasonal with long drier season \\
\hline $1.00-1.19$ & Most rain in 3 months or less \\
\hline$\geq 1.20$ & Extreme, almost all rain in $1-2$ months
\end{tabular}

Source: Walsh and Lawler (1981) 
below the normal. This fall in rainfall and occurrence of droughts will obviously lead to a fall in the general quantity of water supply in Bamenda I.

\section{Impacts of Rainfall Variability on Water Supply}

This section deals with the effects of variation in rainfall on water supply. These variations in rainfall pattern and amount have caused several impacts on the water system. They include intense erosion within river channel leading to occurrence of landslides, sedimentation in water collection chambers leading to its blockage, and erosion along pipeline network leading to breakage. Also, meteorological droughts lead to shrinking of rivers and springs. It equally shows the Pearson's correlation coefficient between monthly rainfall amount and water supply.

\section{Pearson's Correlation Coefficient Between Rainfall Variability and Water Supply}

The Pearson's correlation coefficient is a measure of the linear correlation between two variables. It is a tool for determining the strength of a relationship existing between two variables. It was therefore used to establish the relationship between rainfall and water supply in Bamenda I.

From Table 3, the Pearson's correlation coefficient is 0.701 . This positive value shows a direct relationship between monthly rainfall and monthly water supply in Bamenda I. Meaning that an increase in rainfall amount will lead to an increase in quantity of water supply while a fall in rainfall will condition a fall in water supply quantity (in monthly or seasonal bases). This is because an increase in rainfall amount due to the outbreak of the rainy season will progressively recharge the water table and increase its level thereby increasing the volume and level of surface and groundwater, respectively, this will consequently increase quantity of water abstracted and supplied in the municipality.

Though the correlation coefficient indicates a strong positive relationship $(+0.701)$, it is not up to a total positive relationship $(+1)$, implying that other factors influence quantity of water supply in Bamenda I. To determine their contribution, the coefficient of determination was calculated, and the proportion of rainfall was determined. This coefficient gave an $\mathrm{R}^{2}$ value of 0.49 and a rainfall proportion of $49.14 \%$. This percentage shows the contribution of rainfall on the changes observed in quantity of water supply, therefore the remaining $50.86 \%$ indicates the contribution of other factors. These factors include demographic increase, urban expansion, infrastructural, and managerial factors.

Table 3 Pearson's correlation coefficient between monthly rainfall variability and water supply

\begin{tabular}{l|l|l|l}
\hline Variables tested & $\begin{array}{l}\text { Pearson's correlation } \\
\text { coefficient }(\mathrm{r})\end{array}$ & $\begin{array}{l}\text { Coefficient of } \\
\text { determination }\left(\mathrm{R}^{2}\right)\end{array}$ & $\begin{array}{l}\text { Proportion of rainfall } \\
\text { in the change }\end{array}$ \\
\hline $\begin{array}{l}\text { Rainfall }(\mathrm{mm}) \text { and } \\
\text { water supply }\left(\mathrm{m}^{3}\right)\end{array}$ & 0.701 & 0.49 & $49.14 \%$ \\
\hline
\end{tabular}

Source: Author (2019) 


\section{High Rainfall Intensity and the Water System}

Occurrence of torrential rains in this area is usually accompanied by heavy downpours, which generally constitutes more of overland flow than infiltration. This is because the steep topography limits chances of infiltrate and rather permits runoff. These conditions will therefore lead to occurrence of surface runoffs, which flow into rivers and increase their volumes. This increase in river volume will increase its force and action within the channel, and this will lead to the occurrence of landslides along its banks. On the other hand, runoffs mostly transport sediments and debris, which ends up blocking water intakes and damaging transmission pipes, thereby preventing water input and output into and out of the system (Plate 1).

As seen on Plate 1, landslides occur due to intense erosive activities along the river course due to intense rainfall episodes (Photo 1). Equally, the transportation of sediments and deposition within the river channel leads to blockage of water collecting chambers and consequently, no inputs into the water system. Also, the occurrence of gully erosion will lead to the exposure of and further damage on pipelines and in such situations, outputting will be hindered, (Photo 3). When these phenomena take place, the entire water system is disrupted, and water crises are witnessed in the municipality.

\section{Droughts and Natural Supply}

When meteorological droughts persist, hydrological droughts develop. The term "drought" can have different meaning to different people, depending on how a water deficiency affects them (Moreland et al. 1993). To the people of Bamenda I, droughts are condition of persistent dryness that leads to a reduction in stream flow and groundwater levels, thereby causing water shortages. Prolonged occurrences of this drought therefore lead to shrinking of their water sources (streams, springs, and wells) and in some cases, it leads to the complete disappearance of some streams, (Plate 2).

As seen on Plate 2, there is a drastic fall in the volume of stream flow (Photo 1), shrinking of springs (Photo 2), and complete disappearance in stream flow as seen on Photo 3. These situations are found in Nkar, Ntanche, and Alahnting, respectively.

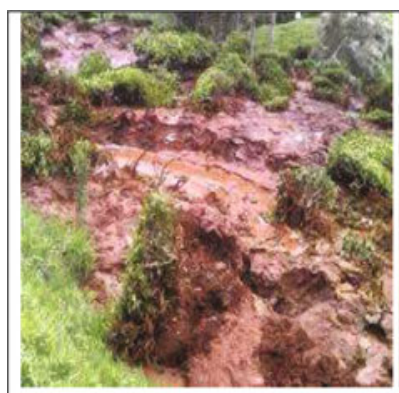

Photo 1

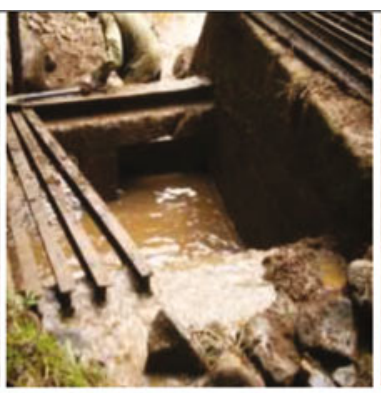

Photo 2

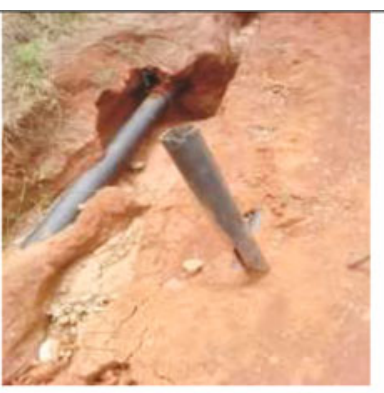

Photo 3

Plate 1 Impacts of heavy downpour on the water system 


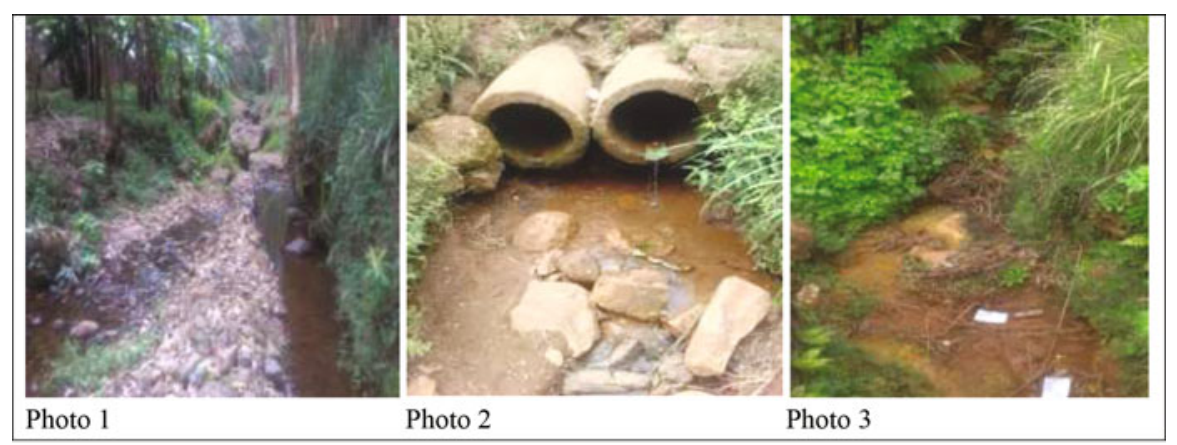

Plate 2 Impacts of drought on natural supply

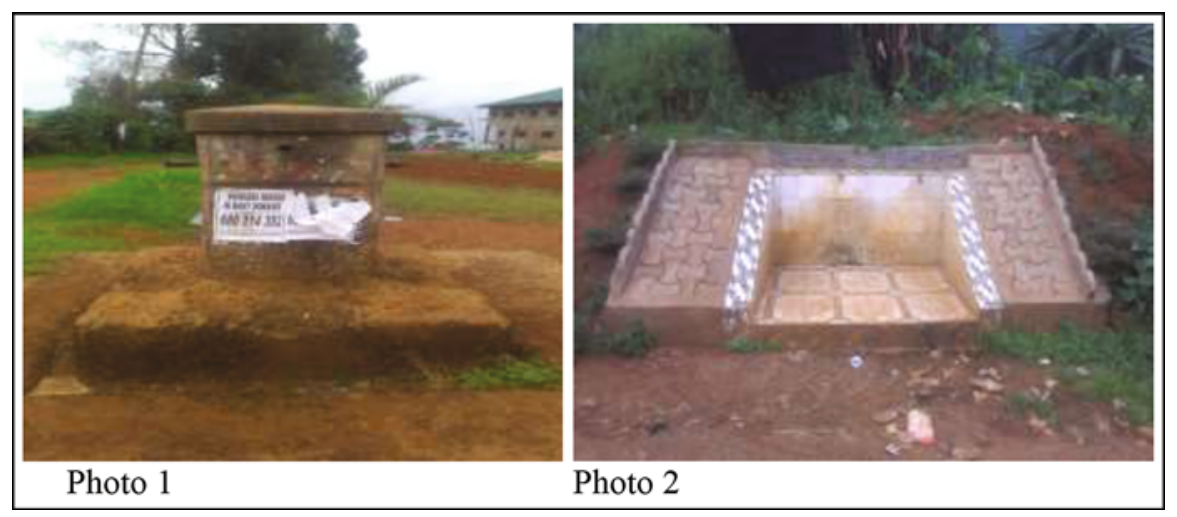

Plate 3 Impacts of drought on supply points

This is caused by three main factors: firstly by lack of precipitations to recharge surface and groundwater, secondly by prolonged evaporation that lead to direct water lost, and lastly by uptake and transpiration from vegetation that reduce both ground- and surface water. Intense insulation and high temperatures often amplify this situation. This result supports the thesis of Adefolalu (1993). On the idea that "climate change can lead to drying up of springs and is projected to reduce surface and ground water resources significantly in most subtropical regions." This reduction in stream flow will reduce quantity of natural supply, thereby reducing input of water to the system, and this will lead to a drastic reduction in total quantity of water supplied within the municipality.

This fall in supply has led to the shutdown of most public supply spots since available water quantity is no longer sufficient to supply all points, (Plate 3).

Plate 3 illustrates shutdown of water supply points due to scarcity in water resource. This is the case of Akumbele and Ntafebuh on Photos 1 and 2, respectively. This occurs because a fall in natural supply due to meteorological drought will lead to a reduction in input to the water system. This reduced in input will lead to a 
reduction in the quantity of water abstracted and stored in reservoirs, consequently, there will be shutdown of most public supply points since water quantity is no longer enough to freely satisfy the population.

\section{Adaptation Measures}

Households and stakeholders have put in place a wide range of measures to adapt to rainfall variability and reduce its effects on water supply in Bamenda I. They range from drilling of boreholes and wells, spring source coverage, use of rainwater collection systems (during rainfall episodes), and through the application of water catchment protection and management measures such as construction of life fences, planting of water friendly trees, slanting and enlarging river banks, and engaging the local population in catchment protection.

\section{Drilling of Boreholes Wells}

Surface water sources have become exposed and vulnerable to climatic and environmental hazards such that people were forced to adapt through use of alternative water source. This change was from the use and dependence on surface water sources to groundwater source, which are less exposed and sensitive to the effects of climatic hazards. These surface water sources include boreholes and well.

\section{Spring Source Coverage}

To reduce the effects of runoffs, mudflow, and consequent pollution on spring source, the local population constructs protective layers on spring sources. These layers are locally constructed using cement and sand (Plate 4, Photo 2). This is done by joint contribution from the inhabitants of the quarters concerned.

\section{Use of Rainwater Collection System}

The use of rainwater over the years has gained its importance as a valuable alternative or supplementary water resource. This is due to the growing scarcity of

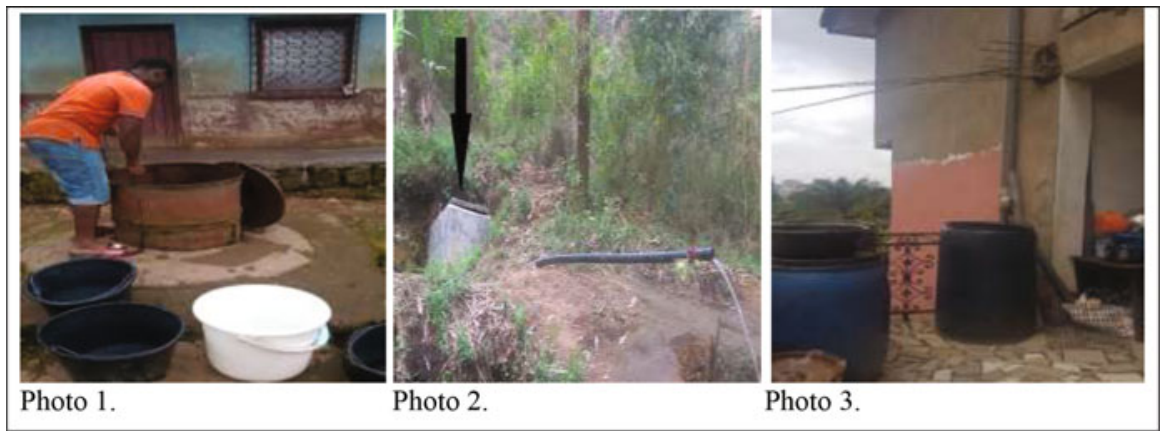

Plate 4 Adaptation to climate-induced effects on water sources 
ground- and surface water caused by extreme weather conditions. Households therefore witness waters shortage and seizures in the dry season as well as in the rainy season. Seizures in the rainy season are often because of intense rainfall that creates damages around stream catchments preventing water inputs and limiting supply. To remedy water shortage during these periods, some households install rainwater collection systems to increase their water supply. Others use containers to collect water dripping directly from roofs. All these measures are clearly illustrated on Plate 4.

Plate 4 illustrates adaptation measures mainly by the local population to combat the effect of climate extreme on water sources in other to maintain and perhaps increase domestic supply quantity. Photos 1, 2, and 3 shows use of wells, spring source coverage, and rainwater collection system, respectively.

Photo 1 shows a domestic well, and it consists of a digged hole down to the water level. Its water is stored within the hole, and its depth is less compared to that of a borehole. This water source is less vulnerable to climatic extremes, and it ensures a steady supply regardless of seasons. Its steady supply is because it is alimented by aquifers, which are less vulnerable to extreme weather conditions. This water source is therefore used as an adaptive source.

The arrow in Photo 2 points out the protection chamber constructed on a spring outflow. This is to prevent the runoff and mudflow into spring sources. This preventive measure will ensure steady water supply without interruptions especially during and after rainy periods. This situation is common in Ntanche and Aningdoh, respectively. Photo 3 illustrates a household rainwater collection system and this system is used to harvest and store water from roofs during rainfall episodes. Rainwater harvesting and storage is done with pipes, which are connected to gutters permitting to link water from the roof to the storage containers. Water is harvested and stored for further use, especially when the stream supply system fails.

Other domestic measures of adapting to water shortage brought by extreme weather conditions includes: increase use of storage containers, buying mineral water from shops and from water vendors, regulating water use, use of stream water, and practicing of household water treatment and storage measures. Those with borehole at times use generators to pump water into reservoirs during periods of power failures. This is common in dry season due to a fall in dam discharge caused by excess meteorological drought that reduces water recharge in the dams. This reduction in water recharge reduces power supply to the electrical system, and this increases the rate of power failures. As such, those with electrical-based water systems are forced to use alternative power supply measures to electrify their systems. The frequency of implementation of adaptation measures depends on the extent to which rainfall variability affects their sources of supply.

\section{Adaptation Through Catchment Protection and Water Management Measures}

Water catchment management (WCM) refers to a range of measures and policies implemented on water catchment in other to reduce environmental, climatic, and anthropogenic actions. It equally involves the management of water catchment 
through taking precautionary measures to prevent or reduce environmental and climatic hazards on drainage basins and or catchment areas. It also concerns the sustainable use of water resource and land within the watershed. Actors involved in these activities include the Ministry of Water and Energy (MINEE), the Cameroon Water Utility Corporation (Camwater), and the Bamenda I sub divisional council. There is equally the role of the local community and anonymous individuals. These WCM measures are aimed at providing sustainable supply of water in terms of both quantity and quality of water. They include:

\section{- Construction of life fences.}

To fight against erosion, there was the planting of life fences round the water catchment areas, both by the subdivisional council and the Camwater. These fences are made of wires and backed up by trees to prevent excess erosion from the surrounding into catchment and river channels. They equally help to prevent grazers from invading the catchment with their cattle. All these measures reduce the rate of damages by erosion on river channel as well as prevent the abuse of water resource by grazer.

- Planting of water friendly trees.

To combat the problem of excess hydrological droughts in Bamenda I, there was a massive planting of water conservation trees (50,000 Pygeum africanum tree) around water catchments. This was done by both the Bamenda I subdivisional council and the Bamendakwe Development and Cultural Association (BAMEDCA). This tree has a little quantity of water uptake and disfavors transpiration. It equally has a large canopy that sheds the catchment and prevents evaporation. Its roots equally hold soil particles together, thereby limiting occurrence of landslides in water catchment. On the other hand, there is a strict restriction on the planting of eucalyptus trees around water catchments. This is due to their high water needs and uptake. All these reduce the level of water lost, thereby conserving water within catchments and ensuring sustainable supply.

\section{- Slanting and enlarging riverbanks.}

Due to the occurrences of landslides along river courses, there was the need to dig along riverbanks in other to gentle the slopes and reduce the action of gravity, which often bring down landmasses along steep riverbanks. Slanting in most cases widens the riverbed, this reduces both the level and the strength of river flow, and this will therefore reduce the erosive action of the river on its banks. This activity is at times accompanied by the planting of trees along river banks which hold soil particles together and reduce the movement and land masses into river channels. This activity is mostly carried out by Camwater.

- Engaging local population in catchment protection.

This involves giving scientific knowledge to the local population on how the catchment operates, thereby permitting them to protect the water catchment at the local level and ensuring a lasting supply of water in catchments. This includes sensitizing the local population (especially those around the catchment) on sustainable agricultural practices around the catchment, such as the importance of agroforestry and antislope wise cultivation in other to prevent and reduce 
excess erosion and deposition of sediments in river channels. It equally concerns placing restrictions on practices such as grazing within water catchment, farming, and deforestation along river courses. It also involves restriction on waste disposal in river channels and around water catchments, since solid and liquid waste disposal in rivers and open space leads to diverse kind of health problems including water and airborne diseases (Achancheng et al. 2003). On the other hand, this is concerned with the massive participation of the entire community around water catchment during activities such as planting of trees and building of life fences. A reduction in these activities and participation of the local population will provide a friendly milieu for conservation of water in the catchments and hence to improve water resources while ensuring the productivity of any water body for the community that depends on it.

Adaptation measures are equally implemented on storage and distribution facilities. This was in a bit to increase water collection, storage, and hence distribution.

\section{Adaptation on Storage Facilities}

To address the problem of water lost to the environment by natural springs, amendments were made on spring sources and reservoirs constructed on them to collect and store flowing water. There was equally the construction of water tower to abstract and store water from aquifers, all these in a bit to store water and prepare for periods of high water demand. Doing so equally reduces the direct impacts of climate extremes on springs especially pollution from runoff and mudflow due to intense rains. This was done by the Bamenda I subdivision council and by the CameroonChina cooperation. These reservoirs were constructed at Menka, Abangoh, and Mendankwe with a carrying capacity of $18 \mathrm{~m}^{3}$ each.

\section{Adaptation on Distribution Facilities}

To limit the damaging action of erosion, floods, and other external factors on pipelines, the water management committee proceeded to the use of metallic pipes on strategic points (in highly vulnerable zones to erosive actions) on the distribution network. There was equally a considerable increase in depth of pipelines especially in areas with loosed soil particles. These were aimed at minimizing damages on pipe network in other to maintain supply. The water management committee equally puts in place distribution trucks (mobile reservoir) to ensure supply especially to extreme quarters on the distribution network. This is mostly common in the dry season were pressure is not enough to pump water to all localities due to low water levels in reservoirs. This service is common in Achichum, which is furthest on the distribution network, and sometimes in Ayaba, which is higher in altitude. In most cases, the trucks are recharged in areas with adequate water supply and distributed in those with limited supply. All these facilities will therefore increase supply in periods of shortages and in vulnerable zone, thereby increasing the total quantity of water supply in Bamenda I. In addition, during situations where available water cannot adequately satisfy the entire population, there is water rationing to ensure equitable supply to all subscribers. 


\section{Conclusion and Future Prospects}

Rainfall is one of the climate parameters which affect water in the entire drainage basin, thereby leading to consequent effects on rivers and their tributaries. This study was based on the impact of rainfall variability on the quantity of water supply in the Bamenda I municipality. Rainfall amounts in the municipality fluctuate around the normal. Its variability is indicated through fluctuations in interannual rainfall variability and anomalies, and through monthly rainfall variability and anomalies. These anomalies are either positive or negative indicating periods of more or less rainfall amounts. Rainfall variability equally manifests through variations in number of rainy days and through fluctuations in rainfall intensity. The rainfall regime was gotten using climatic indices, and the Pearson's correlation coefficient was conducted to determine how quantity of water supply responds to rainfall variability. However, rainfall conditions seasonal variation in quantity of water supply to an extent, since supply is generally higher in rainy than dry seasons (direct relationship), though some cases occurred where periods of intense rainfall instead leads to a drastic reduction in supply (inverse relationship). Extreme weather events such as heavy rains, flooding, and drought are increasingly becoming common in the municipality. Their occurrence distorts the functioning of both the hydrological cycle and the water system, thereby affecting the quantity of water supply in the municipality.

\section{Future Prospects}

Since the study was carried out in the Bamenda I municipality (Bamenda highlands), there is need for further research to expand the geographical scope of the study, in other to do a comparative study of two different drainage basins or water catchments to assess the level of responsiveness of water resources to rainfall variability.

Result from the study showed that beside rainfall variability, there exist other factors, which greatly affect quantity of water supply in Bamenda I. Therefore, further research should be carried out in other to access the validity of these factors.

Equally, an improvement in hydrological research will provide a room for adaptation measures. This is because more research in the domain of water supply will identify more threat to the natural functioning of water catchments (drainage basins), and therefore more suggestion will come up to improve adaptation measures on water catchment.

\section{References}

Achancheng E, Lydie SA, Temitope DT, Corntin YC (2003) Urban cities and waste generation in developing countries: a GIS evaluation of two cities in Burkina Faso

Adefolalu (1993) Precipitation, evapotranspiration and the ecological zones in Nigeria Dhaka. http://www.wateraid.org/documents/plugin_documents/060721_tubewell_guidelines.pdf Flyer, Bamenda I Council (2018) Physical and human environment of Bamenda 1. $\mathrm{http}: / /$ www.google.com $/$ search?q=pangire + date + of + creation\&client $=$ ucweb-b\&channel $=\mathrm{sb}$ 
http://www.who.int/water_sanitation_health/publications/vision_2030_summary_policy_implicati ons.pdf

Hayward O, Mata LJ, Arnell NW, Döll P, Kabat P, Jiménez B (1987) Climate and Chlorophyll: Long-term trends in the central North Pacific Ocean

IPCC (2008) Climate change and water. Intergovernmental Panel on Climate Change Working Group II technical support. Jewitt, G.P.W, Schulze R.E (1999). Verification of the ACRU model for forest hydrology applications. Water SA 25:483-489

IPCC (2014) Managing the risks of extreme events and disasters to advance climate change adaptation. A special report of Working Groups I and II of the intergovernmental panel on climate change. Cambridge University Press, Cambridge

Jiduana GG, Dabi DD, Dia RZ (2011) The effects of climate change on water and agricultural activities in selected settlements in the Sudano-Sahelian Region of Nigeria. Arch Appl Sci Res 3:154-165

Mark E, Andrew A, Joseph L, Jamie B (2008) HWTS education: a hidden success in emergency situations" Presentation at the "Water and Health: Where Science Meets Policy" conference. Chapel Hill, USA. October 26, 2010

McKee TB, Giddingset, Nolan J (1993) Standard precipitation index (SPI) and methods of accessing rainfall variability. The Relationship of Drought Frequency and Duration to Time Scales. 8th Conference on Applied Climatology, Anaheim, 17-22 January 1993

Moreland (1993), Burdon DJ (1985). Groundwater against drought in Africa. In Hydrogeology in the Servic of Man, Mémoires of the 18th Congress of the International Association of Hydrogeologists. Cambridge. http://iahs.info/redbooks/a154/iahs_154_02_0076.pdf Accessed 11 November 2010

PANGIRE (2013) Plan D’Action National de Gestion Intégrée des Ressources en Eau: Etat des lieux du secteur

Parry ML, Palutik JP, Van Der Lind PJ (2007) Water supply sanitation (WSS) in Moldova, climate change: impacts, adaptation and vulnerability. Contribution of working group II to the Intergovernmental Panel on Climate Change. Cambridge University Press, Cambridge

Tsalefac M (2007) Variabilité climatique, crise économique et dynamique des milieux agraire sur les Haute terres de l'ouest Cameroon. Thèse de Doctorat d'Etat de lettre et the science humaine, spécialité, option climatologie, Université de Yaoundé, 564p

Tsalefac M, Ngoufor R (2007) Afrique Centrale, le Cameroun et les changements globaux

Walsh R.P.D, Lawler D.M (1981) Methods of determining seasonality index and methods of accessing rainfall regimes. Rainfall seasonality: Description, spatial patterns and change through time

Wilby RL (2006) Van Vliet and Zwolsman (2008) A framework for assessing uncertainties in climate change impacts, low-flow scenarios for river Thames, UK Sustainable land and water management policies and practices: a pathway to environmental sustainability in large irrigation systems. Land Degrad Dev 19:469-487

Open Access This chapter is licensed under the terms of the Creative Commons Attribution 4.0 International License (http://creativecommons.org/licenses/by/4.0/), which permits use, sharing, adaptation, distribution and reproduction in any medium or format, as long as you give appropriate credit to the original author(s) and the source, provide a link to the Creative Commons license and indicate if changes were made.

The images or other third party material in this chapter are included in the chapter's Creative Commons license, unless indicated otherwise in a credit line to the material. If material is not included in the chapter's Creative Commons license and your intended use is not permitted by statutory regulation or exceeds the permitted use, you will need to obtain permission directly from the copyright holder. 